\title{
Changes in body weight and health behaviors of overweight children during the COVID-19 pandemic
}

\section{Mudanças na massa corporal e em comportamentos de saúde de crianças com excesso de peso durante a pandemia da COVID-19}

\section{AUTHOR'S \\ Gabriel Gustavo Bergmann ${ }^{1}$ (D) \\ Gabriel Barros da Cunha ${ }^{1}$ (iD) \\ Gicele de Oliveira Karini da Cunha ${ }^{1}$ (iD \\ Julie Hellen de Barros Cruz ${ }^{1}$ (D) \\ Lorena Rodrigues Silva ${ }^{1}$ (D) \\ Gustavo Dias Ferreira ${ }^{1}$ (D) \\ Eraldo dos Santos Pinheiro ${ }^{1}$ (D) \\ 1 Universidade Federal de Pelotas, Departamento de Educação Física, Pelotas, Rio Grande do Sul, Brasil.}

\section{CORRESPONDING}

\section{Gabriel Gustavo Bergmann}

gabrielgbergmann@gmail.com

Universidade Federal de Pelotas (UFPel),

Escola Superior de Educação Física (ESEF/

UFPel). Rua Luís de Camões, 625, Três

Vendas, Pelotas, Rio Grande do Sul.

CEP: 96055-630.

DOI

$10.12820 /$ rbafs. $25 \mathrm{e} 0153$

\section{(cc) BY}

This work is licensed under a Creative Commons Attribution 4.0 International License.

\begin{abstract}
The aim of this study was to describe the perception of parents of overweight children about the effects of the period of social distancing due to COVID-19 on body weight (BW), level of physical activity (PA), time spent in sedentary behavior $(\mathrm{SB})$ and their children's eating habits and sleep. Parents of 47 overweight children (11.1 \pm 1.33 years) were interviewed by telephone. Questions about the perception regarding BW and the four behaviors related to the health of their children during the period of social distancing were asked. The increase in BW was perceived by $61.7 \%$ of children and for almost all of them (93.6\%) reductions in PA levels were reported, with $72.4 \%$ reducing participation in vigorous PA. An increase in time using smartphones, tablets, and microcomputers was observed in $65.9 \%$ of children. Favorable changes were noted in relation to quality (34.1\%) and daily sleep time (51.1\%). Favorable changes in the consumption of fruits (36.2\%) and soft drinks (21.2\%) and unfavorable changes in the consumption of vegetables (19.1\%) and sweets and snacks $(26.2 \%)$ were also reported. Four and a half months after the start of the social distancing measures due to the COVID-19 pandemic, overweight children increased the BW and changed the levels of PA and $\mathrm{SB}$ in an unfavorable way according to their parents. On the other hand, they started sleeping more and with higher quality and consuming more fruits and less soft drinks.
\end{abstract}

Keywords: Behavior change; Obesity; Children; Health.

RESUMO

O objetivo deste estudo foi descrever a percepção de pais de crianças com excesso de peso sobre os efeitos do periodo de distanciamento social devido à COVID-19 na massa corporal (MC) no nivel de atividade física $(A F)$, no tempo em comportamento sedentário (CS) e nos hábitos alimentares e de sono de seus filhos/as. Pais de 47 crianças (11,1 $\pm 1,33$ anos) com excesso de peso foram entrevistados por ligação telefônica. Questöes sobre a percep̧ção em relação à $M C$ e aos quatro comportamentos relacionados à saúde de seus filhos/as durante o periodo de distanciamento social foram realizadas. O aumento de $M C$ foi percebido para $61,7 \%$ das crianças e para quase todas elas (93,6\%) reduçôes nos niveis de AF foram relatadas, tendo 72,4\% reduzido a participação em AF vigorosas. Aumento no tempo utilizando smartphone, tablet e microcomputador foram percebidos em 65,9\% das crianças. Modificaçôes favoráveis foram percebidas em relação à qualidade $(34,1 \%)$ e ao tempo diário $(51,1 \%)$ de sono. Modificações favoráveis relativas ao consumo de frutas $(36,2 \%)$ e de refrigerantes $(21,2 \%)$ e desfavoráveis para o consumo de verduras e legumes $(19,1 \%)$ e de doces e salgadinhos (26,2\%) também foram relatadas. Após quatro meses e meio do início das medidas de distanciamento social devido à pandemia da COVID-19, de acordo com a percepção de seus pais, crianças com excesso de peso aumentaram a MC e modificaram de forma desfavorável os niveis de AF e CS. Por outro lado, passaram a dormir mais e com maior qualidade e a consumir mais frutas e menos refrigerantes.

Palavras-chave: Mudança de comportamento; Obesidade; Crianças; Saúde.

\section{Introduction}

Since the end of 2019 the world has faced the Coronavirus Disease (COVID-19) pandemic ${ }^{1}$. The main and most effective measure to combat the virus is the social distancing ${ }^{2}$. However, this has led to a drastic change in the populations' lifestyle with repercussions in different health markers. Such repercussions may vary regarding to type, frequency, intensity and dura- tion according to individual, social and environmental features. Although this affects individuals from all ages, there is a growing concern about children's health not only during the pandemic, but also in relation to its possible long-term effects ${ }^{3-6}$.

The schools closing as part of the social distancing, although highly recommended and necessar $y^{6,7}$, may generate unfavorable changes in different health-re- 
lated behaviors of the children contributing for a propitious framework for the body weight (BW) gain ${ }^{4,5}$. This hypothesis is reinforced from results of studies indicating that this set of behaviors tends to change to lesser favorable patterns in periods that children are out of the schools, such as on weekends, prolonged holydays and school vacations ${ }^{8,9}$. Considering the schools have been closed for more than five months and there is still no forecast of returning face-to-face classrooms activities, it is possible to speculate that these behavior changes are even greater during the COVID-19 pandemic period.

Although behavioral changes with a negative impact on children's health markers during the pandemic period were expected ${ }^{4,5}$, for some subgroups these changes may occur in a more pronounced way. Overweight and obese children are less physically active, remain more time in sedentary behavior (SB) and have eating habits $(\mathrm{EH})$ and sleep habits $(\mathrm{SH})$ less favorable than normal weight children ${ }^{10-14}$. Besides, a less favorable profile in mental health markers is also more often among overweight and obese children than those in normal weight condition ${ }^{15,16}$. Such features may contribute so that the adverse health effects caused by social distancing are enhanced in overweight and obese children ${ }^{17}$.

Given the above, it is important that overweight children's behaviors be monitored throughout the pandemic. Access to this information may support the development of counseling and support strategies for parents, teachers and education departments to organize a healthier routine during and after the COVID-19 pandemic period. The aim of this study is to describe the perceptions of overweight children's parents about the effects of social distancing due to COVID-19 pandemic on BW, physical activity (PA) levels, time spent in $\mathrm{SB}$, and on $\mathrm{EH}$ and $\mathrm{SH}$ of their children.

\section{Methods}

This descriptive study of a quantitative approach was carried out contacting parents of overweight children from public schools who were part of an intervention project conducted during 2019 July and December in a Southern city from Brazil. Considering the recommendation for the social distancing as a main measure to combat the COVID-19 pandemic, the study's data collection was performed by telephone interview with the parents of the children. During the data collection period, the Rio Grande do Sul state has been declared a state of public calamity in all its regions and that the city where this study was carried out followed the recommendations of the state government for social distancing, restricting circulation, visits and face-to-face meetings of any kind to what is strictly necessary. This study was analyzed and approved (number: 4.127.281) by the Ethics Committee in research involving human beings from the institution where it is registered.

The participants' selection was carried out considering the total of 65 overweight children who took part in the intervention project. The telephone's contacts of at least one parent of each of the 65 children were available and all of them were included to participate in the study. Contacted parents who reported not living with the children daily during the COVID-19 pandemic period were excluded and the contact of other guardian who was living with the child was requested. Calls that after different attempts were not answered were considered losses.

The calls were made during the last week of July and the first week of August 2020, approximately four and a half months after the closing of schools and of other measures to combat the COVID-19 pandemic. Following standardized procedures three members of the research team performed up to ten call attempts to the telephone numbers on which calls were not answered, redirected to the mailbox or automatic responses informing that the phone number were not available or did not exist.

For the answered calls, the research team members asked to talk with one parent or guardian of the children. Initially, the interviewers introduced themselves and asked if the parent was living with the children daily during the pandemic period. If the response was negative, the telephone of another guardian was requested. For positive responses, the aim, the rationale and the procedures of the study were explained. If the parents agreed to participate in the study, the interview was performed at the moment or scheduled for a time that best suited the interviewee. The calls lasted approximately 12 minutes.

The data collection instrument was organized in six blocks: sociodemographic characteristics (gender, age, family income - monthly minimum wages - and, who answered to the interview), BW, PA levels, time in SB, $\mathrm{EH}$ and $\mathrm{SH}$.

The parents' perception about the children's BW was based on the following question: Compared to the period that your child was attending the school, do you think that during these period of social distancing his/ 
her BW is: a) much higher; b) higher; c) equal; d) lower; e) much lower.

The parents' perception about the possible changes in the four health-related behaviors of the children was based on the answers to the blocks of questions about indicators of $\mathrm{PA}, \mathrm{SB}, \mathrm{EH}$ and $\mathrm{SH}$. The first question for each behavior's block was about a general perception in relation to the possible changes during the social distancing due to COVID-19 pandemic. All questions were structured comparing the current situation, during the pandemic period, with the period in which their child was attending the school.

Before starting the questions about PA, parents were informed that PA is any activity in which child performed body movement, as commuting, domestic chores, personal hygiene, active play and games, sports, dance, gymnastics, etc. In addition, it was explained that there are differences among light, moderate and vigorous PA. Light PA are body movements that children perform without much effort and that there are no severe change in breathing. Moderate PA is any activity in which children perform some physical effort and that makes breathing a little harder than normal. Vigorous PA is any activity in which children perform substantial physical effort and that makes breathing much harder than normal. The parents' perception about children's PA was based in four questions: The first one was about a general perception of PA level and the others ones regarding light, moderate and vigorous PA, respectively. For all questions the answers options were: a) much less b) less c) equal; d) more; e) much more.

Before asking questions about children's time in SB, parents have received explanations that $\mathrm{SB}$ is any activity in which children are siting, reclining or lying down (without being sleeping). The parents' perception regarding children's time in SB was based on four questions. The first question was about the general perception of the children's time in SB. The second about time watching TV, the third about time playing videogame and the fourth about time using smartphone, using tablet and/ or using microcomputer recreationally. The answers options for all questions regarding time in SB were: a) much less b) less c) equal; d) more; e) much more.

For the parents' perception in relation to children's $\mathrm{EH}$, five questions were carried out. The first one was about the general perception of the children's $\mathrm{EH}$ having as answer options: a) much worse; b) worse; c) equal; d) better; e) much better. The other four questions were in relation in relation to fruits eating, vegetables eating, sweets and snacks eating and soda drinking. The answer options for these questions were: a) she/he does not consume it; b) much less c) less d) equal; e) more; f) much more.

The parents' perception about the children's SH was considered based on four questions. The perception about children's sleep quality was the first one. The second question was about children's total sleep time. The answer options for these both questions were: a) much higher; b) higher; c) equal; d) lower; e) much lower. The third and fourth questions were based on times to go sleeping and waking up, respectively. Options of answers for these questions were: a) much earlier; b) earlier; c) equal; d) later; e) much later.

Sociodemographic characteristics were described using mean, standard deviation (numerical variables) and absolute and relative frequencies (categorical variables). For the analysis and presentation of the parents' perception about the possible changes in BW and in health-related behaviors of the children, the answers were standardized in "much unfavorable changes", "unfavorable changes", "no changes", "favorable changes" and "much favorable changes". For the questions about EH regarding fruit eating, vegetables eating and soda drinking were kept the answer options "she/he does not consume it". The answer options for SH regarding children's times for sleeping and waking up were kept as described above. Based on the answers for the firsts questions in each health-related behavior were described the children's proportions in which parents perceived favorable and unfavorable changes in none, one, two, three or four behaviors. For this analysis the answer options "much unfavorable changes" and "unfavorable changes" were grouped as "unfavorable" and the answer options "favorable changes" and "much favorable changes" were grouped as "favorable".

\section{Results}

Phone calls were performed to the parents of the 65 overweight children. Of these, 47 answered the calls and said they were living with the children on a daily basis and have agreed to participate in the study (38 mothers and nine fathers). After 10 attempts at different days, it was not possible to contact parents of 18 children. The children's mean age was 11.1 ( \pm 1.33 ) years old, most of them were males and from families with less than two minimum wages (Table 1 ). 
Table 1 - Characterization of the participants.

\begin{tabular}{lc}
\hline Sociodemographic variables $(\mathrm{n}=47)$ & \\
\hline Gender & $31(66.0 \%)$ \\
Male (n; \%) & $16(34.0 \%)$ \\
Female (n; \%) & $11.1(1.33)$ \\
Age (years) $(\overline{\boldsymbol{X}}$ e SD) & $25(54.3 \%)$ \\
$\leq 11$ years $(\mathrm{n} ; \%)$ & $22(45.7 \%)$ \\
$>11$ years $(\mathrm{n} ; \%)$ & $2.2(1.41)$ \\
Family income $(\overline{\boldsymbol{X}}$ e DP) & $28(59.6)$ \\
$<2$ minimum wages $(\mathrm{n} ; \%)$ & $15(31.9 \%)$ \\
$2-4$ minimum wages $(\mathrm{n} . \%)$ & $4(8.5 \%)$ \\
$>4$ minimum wages $(\mathrm{n} ; \%)$ & \\
Parent interviewed & $38(80.9 \%)$ \\
Mother (n; \%) & $9(19.1 \%)$ \\
\hline Father $(\mathrm{n} ; \%)$ &
\end{tabular}

$\mathrm{n}=$ number of participants; $\%$ = proportion of participants; $\bar{x}=$ mean; $\mathrm{SD}=$ standard deviation.

Results regarding the parents' perceptions about body weight and the four health-related behaviors of the children over four and a half months of the measures of social distancing and schools closures due to the COVID-19 pandemic are illustrated in Figure 1. According to parents' perceptions, $61.7 \%$ of the children have increased their BW (much unfavorable and unfavorable change). Levels of PA and time in SB were the behaviors in which unfavorable changes have occurred in higher proportion. Parents of $93.6 \%$ of the children have perceived reductions in PA levels of the children, with greater reductions perceived for vigorous PA (72.4\%). Regarding SB, according to parents' perceptions, $78.7 \%$ of the children increased their daily time in activities performed in the siting, reclining or lying down positions. Activities involving the use of smartphones, tablets and microcomputers were those that a greater number of children showed unfavorable changes (65.9\%).

Unlike the results for PA and SB, the parents' perception about $\mathrm{EH}$ and $\mathrm{SH}$ have indicated lower proportions of children with unfavorable changes in the analyzed indicators (Figure 1). Just over a quarter of the parents have perceived unfavorable changes in children's EH over the social distancing period. However, they also have perceived that just over a third, about a quarter and $21.1 \%$ of the children have started eating more fruits, eating less sweets and snacks and drinking less soda, respectively, over the period. Regarding $\mathrm{SH}$, just over a third of the parents have perceived favorable changes in the sleep quality and nearly half of them have perceived favorable changes in the amount of sleep time of their children. Nevertheless, $85.1 \%$ and $80.9 \%$ of the parents have reported that their children have started going sleep and waking up later, respectively, than they usually did before the social distancing measures has started.

Analyzing just the questions about the general parents' perception of each one of the health-related be-

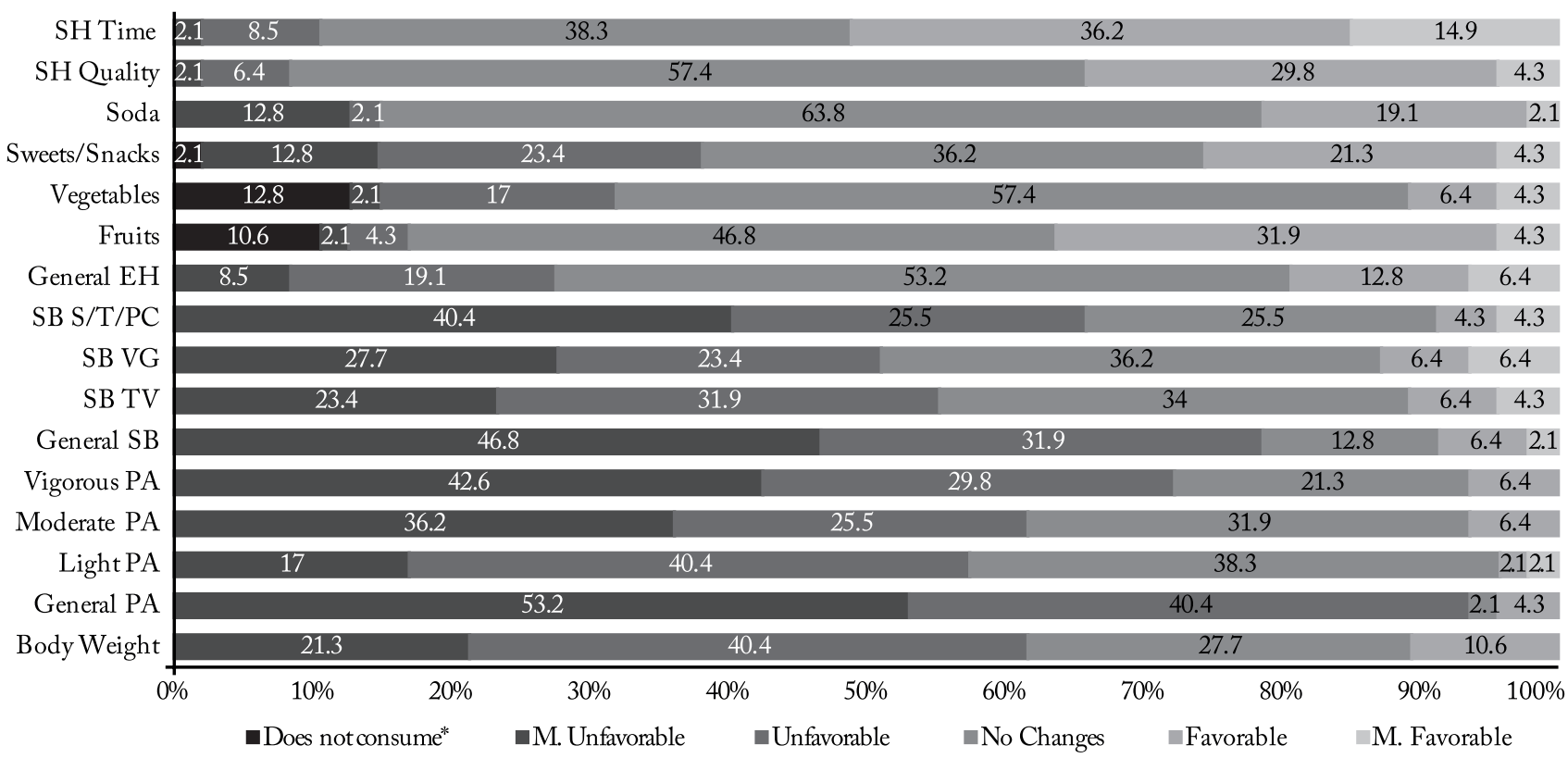

Figure 1 - Parent's perception regarding to the changes in their children's body weight, levels of physical activity, time in sedentary behaviors, eating habit and sleep habits after four and a half months of social distancing due the COVID-19 pandemic. $(\mathrm{SH}=$ sleep habits; $\mathrm{EH}=$ eating habits; $\mathrm{SB}=$ sedentary behavior; $\mathrm{S}=$ smartphone; $\mathrm{T}$ = tablet; $\mathrm{PC}=$ microcomputer; $\mathrm{VG}=$ videogame; $\mathrm{TV}=$ television; $\mathrm{PA}=$ physical activity; $\mathrm{M}=$ much; *answers' options only for Eating Habits ). 
haviors, unfavorable changes in at least one of the four behaviors were identified in $97.9 \%$ of the children. Parents of $10.5 \%$ of the children have perceived unfavorable changes in all of the analyzed behaviors (Figure 2). Just over a third of the parents have perceived favorable changes in at least one of the four analyzed behaviors. None of the parents have perceived favorable changes in all behaviors (Figure 2).

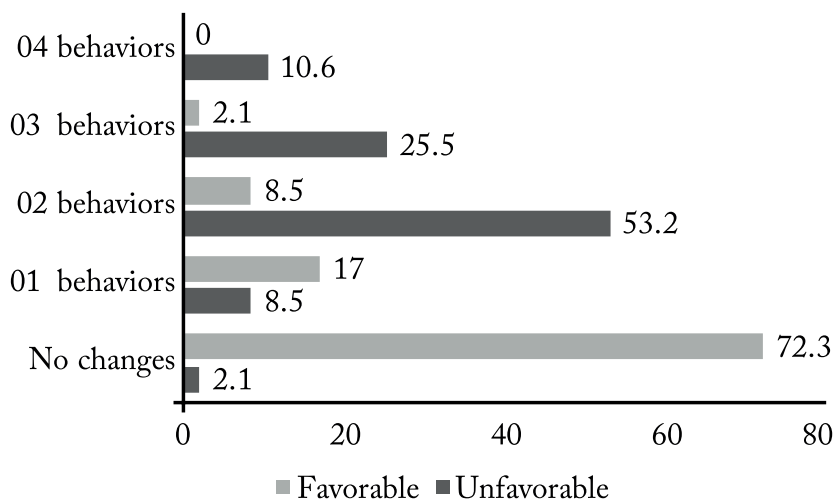

Figure 2 - Proportion of children with favorable and unfavorable changes in health-related behaviors according to their parent's perception.

\section{Discussion}

The aim of this study was to describe the parents' perceptions about changes in BW and in four health-related behaviors of overweight children after four and a half months of social distancing due to the COVID-19 pandemic. In general, children have increased BW and have changed unfavorably the levels of PA and SB. However, favorable changes were reported in the quality and amount of sleep and in the eating fruits and drinking soda.

The schools closing and the suspension of the faceto-face classes were one of the main measures of social distancing to combat the COVID-19 pandemic ${ }^{6,7}$. With these measures it was expected that children would unfavorably change some behaviors, especially those related to PA and to sedentary activities, contributing for the BW gain ${ }^{4,5}$. In a study carried out with adolescents who were regularly involved in sports practice before the pandemic, the BW gain was reported for $29.8 \%$ of the participants ${ }^{18}$. In the present study, BW gain was reported for about $60 \%$ of the children, with a little more than a fifth of them perceiving BW as much higher than before the period of social distancing measures. In addition to being worrying because the proportion of children who increased their BW was more than double that found by Brito et al. ${ }^{18}$. This result deserves attention considering that participants of the present study were already overweight before the COVID-19 pandemic, which may increase the risks associated to overweight to which these children were already exposed.

The increased in the BW may be associated to the unfavorable changes in levels of PA and in SB. The results found in the present study are in line with evidences from research carried out in different part of the world ${ }^{17-21}$, confirming the already expected negative impact of the COVID-19 pandemic in the levels of PA and SB of children and adolescents.

For almost all analyzed children, reductions in PA levels were observed, being that for more than half of them the involvement with PA in general was perceived as much lesser than the period before the COVID-19 pandemic. Although decreases in all intensities of PA have been perceived, for vigorous PA this decrease was still higher. Possibly the higher decrease in vigorous $\mathrm{PA}$ than in moderate and light PA is associated with the decreased participation of children in PA performed outdoors or in specific spaces for sports. Canadian children's parents reported reductions in PA, sports and general playing performed in outdoor by their children ${ }^{19}$. Adolescents who were regularly engaged in some sports practice before the COVID-19 pandemic have reported having reduced $(53.5 \%)$ or not playing any sports during the social distancing period ${ }^{18}$.

As the opportunities for PA practices have reduced and the time inside the home have increased due the social distancing measures, it was expected that unfavorable changes in SB of children and adolescents would occur ${ }^{4,5}$. Compared to the period before school closure, parents of $78.7 \%$ of children perceived increasing in SB time of their children during the social distancing period, with nearly a half of the parents reporting that the time their children spent in these activities was much higher. Among the analyzed types of $\mathrm{SB}$, those involving the using of smartphones, tablets and/or microcomputers were those that showed greatest increase. These results are in line with those found by Moore et al. ${ }^{19}$ and Xiang et al. ${ }^{20}$. Parents of Canadian children have reported that screen time was the health-related behavior that showed the greatest unfavorable changes during the pandemic period ${ }^{19}$, while Chinese children have increased their daily total screen time around four hours ${ }^{20}$.

The parents' perception regarding $\mathrm{SH}$ of the children during the COVID-19 pandemic have indicated that the sleep quality of around a third of them is better and that half of the children increased their sleep time 
compared to the period before the social distancing. Increasing the time and quality of children's sleep or maintenance of these behaviors were reported in previous studies that have investigated children during the COVID-19 period $^{17-19}$. These results suggest that social distancing measures have not impacted unfavorably in the children's $\mathrm{SH}$.

Unlike the PA and SB in which results have suggested unfavorable changes and for $\mathrm{SH}$ that showed favorable changes, results regarding $\mathrm{EH}$ were not homogeneous among the analyzed indicators. Favorable changes regarding children's fruits eating and soda drinking were more often than unfavorable changes according parents' perceptions. On the other hand, unfavorable changes regarding children's vegetables, sweets and snacks eating were more often than favorable changes according parents' perceptions. Results indicating both favorable and unfavorable changes in children's EH during the social distancing period were also reported by Pietrobelli et al. ${ }^{17}$ and Carrol et al. ${ }^{21}$. Perhaps because parents are staying more time of day with their children during the COVID-19 pandemic, they may have stimulated healthier $\mathrm{EH}$ for their children, as fruits eating. The increasing in sweets and snacks eating may be explained because parents and children are staying more time inside their homes. In addition, the increase in children's screen time reported by the parents may be associated with greater consumption of sweets and snacks, as these are behaviors often performed together ${ }^{22,23}$.

As the present study was performed with a reduced number of participants selected by convenience, the results should be interpreted with caution and should not be generalized. However, they are in line with the evidences from studies carried out with large samples ${ }^{18-21}$. Thus, even with this limitation, the results may contribute to the planning of guidance and support actions for parents, teachers, institutions and educational departments to organize healthier routines for children during and after the period of social distancing due to the COVID-19 pandemic. Another limitation refers to the data collection procedures based on parents perception. Although this strategy has also been used in other investigations ${ }^{17,19}$, it may not portray children's behavior.

Although the main findings have already been discussed, the analysis of only overweight children is a characteristic of the present study that should be highlighted. Children in this body condition are more likely to present physical, social and emotional health problems ${ }^{24,25}$ and to becoming obese adults ${ }^{26}$. In addition, overweight children are less physically active, stay longer in $\mathrm{SB}$ and have less favorable $\mathrm{EH}$ and $\mathrm{SH}$ than eutrophic children ${ }^{10-14}$ enhancing the chance of developing these health problems. Results of the present study and those found by Pietrobelli et al. ${ }^{19}$ suggest that these behaviors, mainly levels of $\mathrm{PA}$ and $\mathrm{SB}$, have become even more unfavorable among overweight children during social distancing period. This scenario makes the development of strategies for changing behaviors and promoting a healthy lifestyle for overweight children during and after the pandemic period even more challenging.

In conclusion, after four and a half months of the starting of the social distancing measures due the COVID-19 pandemic, according the parents' perception, overweight children have increased their BW and have unfavorably changed their involvement in PA, mainly those of vigorous intensity, and in sedentary activities. On the other hand, they have started sleeping more and with higher quality and eating more fruits and drinking less soda.

\section{Conflict of interest}

The authors declare no conflict of interest.

\section{Author's contributions}

Bergamnn GG, participated in all stages of the study. Cunha GB, Cunha GOK, Cruz JHB, Silva LR participated in the collection and analysis of data and performed the critical review of the content. Ferreira GD, and Pinheiro ES, contributed to the writing of the manuscript and critical review of the content. All authors approved the final version of the manuscript.

\section{References}

1. Fauci AS, Lane HC, Redfield RR. Covid-19 - Navigating the Uncharted. N Engl J Med. 2020;382(13):1268-69.

2. World Health Organization.Coronavirus disease (COVID-19) outbreak. Geneva: World Health Organization. 2020.

3. Jiao WY, Wang LN, Liu J, Fang SF, Jiao FY, PettoelloMantovani M, et al. Behavioral and Emotional Disorders in Children during the COVID-19 Epidemic. J Pediatr. 2020;221:264-266. e1.

4. Florêncio Júnior PG, Paiano R, Costa AS. Isolamento social: consequências físicas e mentais da inatividade física em crianças e adolescentes. Rev Bras Ativ Fis Saúde. 2020;25:e0115.

5. Rundle AG, Park Y, Herbstman JB, Kinsey EW, Wang YC. COVID-19-Related School Closings and Risk of Weight Gain Among Children. Obesity (Silver Spring). 2020;28(6):1008-1009.

6. Wang G, Zhang Y, Zhao J, Zhang J, Jiang F. Mitigate the effects of home confinement on children during the COVID-19 outbreak. Lancet. 2020;395(10228):945-947. 
7. UNESCO. UNESCO rallies international organizations, civil society and private sector partners in a broad Coalition to ensure \#Learning Never Stops. 26 March 2020. https:// en. unesco. org/news/unesco-rallies-internationalorganizations-civil-society-and-private-sector-partnersbroad (accessed on May 14,2020).

8. Brazendale $\mathrm{K}$, Beets MW, Weaver RG, et al. Understanding differences between summer vs. school obesogenic behaviors of children: the structured days hypothesis. Int J Behav Nutr Phys Act. 2017;14(1):100.

9. Wang YC, Vine S, Hsiao A, Rundle A, Goldsmith J. Weight-related behaviors when children are in school versus on summer breaks: Does income matter? J Sch Health 2015;85(7):458-66.

10. Page A, Cooper AR, Stamatakis E, Foster LJ, Crowne EC, Sabin M, et al. Physical activity patterns in nonobese and obese children assessed using minute-by-minute accelerometry. Int J Obes (Lond). 2005;29(9):1070-76.

11. Olds TS, Ferrar KE, Schranz NK, Maher CA. Obese adolescents are less active than their normal-weight peers, but wherein lies the difference? J Adolesc Health. 2011;48(2):189-95.

12. Firouzi S, Poh BK, Ismail MN, Sadeghilar A. Sleep habits, food intake, and physical activity levels in normal and overweight and obese Malaysian children. Obes Res Clin Pract. 2014;8(1):e70-e78.

13. Vilchis-Gil J, Galván-Portillo $M$, Klünder-Klünder M, Cruz M, Flores-Huerta S. Food habits, physical activities and sedentary lifestyles of eutrophic and obese school children: a case-control study. BMC Public Health. 2015;15:124.

14. Raistenskis J, Sidlauskiene A, Strukcinskiene B, Uğur Baysal S, Buckus R. Physical activity and physical fitness in obese, overweight, and normal-weight children. Turk J Med Sci. 2016;46(2):443-50.

15. Russell-Mayhew S, McVey G, Bardick A, Ireland A. Mental health, wellness, and childhood overweight/obesity. J Obes. 2012;2012:281801.

16. Wang S, Sun Q, Zhai L, Bai Y, Wei W, Jia L. The Prevalence of Depression and Anxiety Symptoms among Overweight/ Obese and Non-Overweight/Non-Obese Children/ Adolescents in China: A Systematic Review and MetaAnalysis. Int J Environ Res Public Health. 2019;16(3):340.

17. Pietrobelli A, Pecoraro L, Ferruzzi A, Heo M, Faith M, Zoller T, et al. Effects of COVID-19 Lockdown on Lifestyle Behaviors in Children with Obesity Living in Verona, Italy: A Longitudinal Study. Obesity (Silver Spring). 2020;10. 1002/oby. 22861.
18. Brito LMS, Boguszewski MCS, Souza MTR, Martins F, Mota J, Leite N. Indoor physical activities, eating and sleeping habits among school adolescents during COVID-19 pandemic. Rev Bras Ativ Fis Saúde. 2020;25:e0117.

19. Moore SA, Faulkner G, Rhodes RE, et al. Impact of the COVID-19 virus outbreak on movement and play behaviours of Canadian children and youth: a national survey. Int J Behav Nutr Phys Act. 2020;17(1):85.

20. Xiang M, Zhang Z, Kuwahara K. Impact of COVID-19 pandemic on children and adolescents' lifestyle behavior larger than expected [published online ahead of print, 2020 Apr 30]. Prog Cardiovasc Dis. 2020;S0033-0620(20)30096-7.

21. Carroll N, Sadowski A, Laila A, Hruska V, Nixon M, Ma DWL, et al. The Impact of COVID-19 on Health Behavior, Stress, Financial and Food Security among Middle to High Income Canadian Families with Young Children. Nutrients. 2020;12(8):E2352.

22. Ekelund U, Brage S, Froberg K, Harro M, Anderssen SA, Sardinha LB, et al. TV viewing and physical activity are independently associated with metabolic risk in children: the European Youth Heart Study. PLoS Med. 2006;3(12):e488.

23. Ferrari GLM, Oliveira LC, Araujo TL, Matsudo V, Barreira TV, Tudor-Locke C, et al. Moderate-to-Vigorous Physical Activity and Sedentary Behavior: Independent Associations With Body Composition Variables in Brazilian Children. Pediatr Exerc Sci. 2015;27(3):380-9.

24. Bass R, Eneli I. Severe childhood obesity: an underrecognised and growing health problem. Postgrad Med J. 2015;91(1081):639-45.

25. Sanders RH, Han A, Baker JS, Cobley S. Childhood obesity and its physical and psychological co-morbidities: a systematic review of Australian children and adolescents. Eur J Pediatr. 2015;174(6):715-46.

26. Guo SS, Chumlea WC. Tracking of body mass index in children in relation to overweight in adulthood. Am J Clin Nutr. 1999;70(1):145S-8S.

Received: 31/08/2020

Approved: 30/10/2020

\section{Quote this article as:}

Bergmann GG, Cunha GB, Cunha GOK, Cruz JHB, Silva LR, Ferreira GD, Pinheiro ES. Changes in body weight and health behaviors of overweight children during the COVID-19 pandemic. Rev Bras Ativ Fis Saúde. 2020;25:e0153. DOI: 10.12820/rbafs.25e0153 